\title{
Cortisol and 17-Hydroxyprogesterone Levels in Saliva of Healthy Neonates
}

\author{
Normative Data and Relation to Body Mass Index, Arterial Cord Blood pH and \\ Time of Sampling after Birth
}

\author{
Ingo Klug a Regina Dressendörfer ${ }^{d}$ Christian Strasburger $^{d}$ \\ Gonne Peter Kühlc Hans-Ludwig Reiter ${ }^{c}$ Andrea Reich ${ }^{a}$ Grit Müller ${ }^{a}$ \\ Kerstin Meyer ${ }^{a}$ Jürgen Kratzsch ${ }^{b}$ Wieland Kiess ${ }^{a}$ \\ aChildren's Hospital, University of Leipzig, and bInstitute of Clinical Chemistry and Pathobiochemistry, Leipzig, \\ 'Children's Hospital, Justus Liebig University of Giessen, Giessen, and dDepartment of Endocrinology, \\ Klinikum Innenstadt, University of Munich, Munich, Germany
}

\section{Key Words}

Cortisol · 17-Hydroxyprogesterone $\cdot$ Neonate $\cdot$ Neonatal stress $\cdot$ Saliva $\cdot$ Circadian rhythm

\begin{abstract}
The measurement of cortisol and 17-hydroxyprogesterone (17-OHP) in saliva has become a reliable tool for both the scientist and the clinician for studying adrenal cortical function in the adult and the older child. We have now established in parallel normative data for salivary cortisol and 17-OHP levels in healthy neonates. We have asked whether or not there is a circadian rhythm of cortisol and 17-OHP saliva levels in neonates. Furthermore, we have asked whether salivary hormone levels correlated with auxologic and clinical data and time of sampling. Cortisol and 17-OHP levels in saliva samples from 119 healthy neonates (55 girls, 64 boys) were measured using in-house time-resolved fluorescent immunoassays. Saliva samples were obtained using a saliva collecting tube three times a day on the first or second day of life. Gender and gestational age did not influence salivary cortisol and 17-OHP levels. No significant circadian
\end{abstract}

\begin{tabular}{ll}
\hline KARGER & ○ 2000 S. Karger AG, Basel \\
Fax +4161306 1234 & 0006-3126/00/0781-0022\$17.50/0 \\
$\begin{array}{l}\text { E-Mail karger@karger.ch } \\
\text { www.karger.com }\end{array}$ & $\begin{array}{l}\text { Accessible online at: } \\
\text { www.karger.com/journals/bon }\end{array}$
\end{tabular}

rhythm of salivary hormone levels was detected in this group of newborns. However, body mass index, arterial cord blood $\mathrm{pH}$ and time of saliva sampling significantly influenced salivary hormone levels. In conclusion, measurement of cortisol and 17-OHP in saliva is feasible in healthy neonates. The existence of normative data forms the basis for future studies on pathophysiologic states in the newborn period.

Copyright ( 92000 S. Karger AG, Basel

\section{Introduction}

Corticosteroids are essential for the development of the fetus. In early neonatal life, cortisol is already of importance for stress responses and metabolic homeostasis. The concentration of cortisol in amniotic fluid increases during gestation towards a maximum at 38-40 weeks of gestation with levels of $82 \pm 12 \mathrm{ng} / \mathrm{ml}[1,2]$.

The 17-hydroxyprogesterone (17-OHP) levels in amniotic fluid in early gestation $(1.63 \pm 0.21 \mathrm{ng} / \mathrm{ml}$, mean \pm SD) are also significantly lower than the levels found later in gestation. From the 36 th to the 38 th week of gestational

\footnotetext{
Wieland Kiess, MD

Children's Hospital, University of Leipzig

Oststrasse 21-25, D-04317 Leipzig (Germany)

Tel +49 3419726000 , Fax +493419726009

E-Mail kiw@server3.medizin.uni-leipzig.de
} 
age, 17-OHP levels reach a maximum of $3.8 \pm 0.74 \mathrm{ng} / \mathrm{ml}$ [3]. High 17-OHP levels in amniotic fluid are found in fetuses with congenital adrenal hyperplasia $[4,5]$.

The transplacental transfer of cortisol and synthetic glucocorticoids has been demonstrated. In the middle of gestation, maternal plasma cortisol levels are 8-10 times higher than the fetal concentrations [6,7]. The relative biologic activity and metabolic rates of glucocorticoids during gestation and at term have been studied previously [8-11].

The measurement of cortisol and 17-OHP in saliva has become a reliable tool for both the scientist and the clinician for studying adrenal cortical function in the adult and the older child [12-15]. We have now established in parallel normative data for salivary cortisol and 17-OHP levels in healthy neonates. In addition, we have asked whether or not there is a circadian rhythm of cortisol and 17-OHP saliva levels in neonates and whether salivary hormone levels correlate with clinical data of the newborns and time of sampling. Cortisol and 17-OHP levels in saliva samples from 119 healthy neonates were measured using in-house time-resolved fluorescent immunoassays. These normative data are expected to build the basis for future studies on pathophysiologic states of adrenal function and stress responses in the newborn period.

\section{Subjects and Methods}

\section{Subjects}

Saliva cortisol and 17-OHP levels were determined in 119 healthy neonates (55 girls and 64 boys). Auxologic and clinical data were recorded using a structured questionnaire (table 1). 25 neonates were born by sectio caesarea, 94 vaginally. Duration of birth was 44$54 \mathrm{~min}$ and the time from onset of labor until birth was $414 \pm 256$ $\min$ in the 94 neonates with vaginal delivery. Saliva was collected $18-24 \mathrm{~h}(\mathrm{n}=21)$ or $25-55 \mathrm{~h}(\mathrm{n}=98)$ after birth.

\section{Saliva Sampling}

From each infant, three saliva samples were taken at 7:00, 13:00 and 19:00 h before meals. Saliva was obtained by using a saliva collecting tube with a cotton swab inside (Salivette ${ }^{\circledR}$, Sarstedt, Nümbrecht, Germany). The cotton swab was left in the neonates' mouth for $5 \mathrm{~min}$. This procedure did not cause any distress. Saliva samples were centrifuged and stored frozen at $-20^{\circ} \mathrm{C}$ until analysis.

\section{Cortisol and 17-OHP Assays}

Samples were analyzed using in-house time-resolved fluorescent immunoassays as described before [12,13]. In some cases, sample volumes were too small for duplicate determination of the two hormones. Therefore, some measures contain smaller sample numbers $(<119)$. In brief, specific polyclonal antibodies against cortisol and 17-OHP respectively were used as first antibodies. Cortisol or 17OHP biotin conjugates were used as tracers. Cross-reactivities of the
Table 1. Anthropometric and clinical data of the 119 healthy neonates investigated in respect to salivary cortisol and 17-OHP levels

\begin{tabular}{lcc}
\hline & Median & Range \\
\hline Gestational age, weeks & 39 & $31-42$ \\
Weight, g & 3,290 & $2,080-4,550$ \\
Length, cm & 51 & $45-57$ \\
Head circumference, cm & 34 & $30-38$ \\
Body surface, $\mathrm{m}^{2}$ & 0.2 & $0.15-0.25$ \\
BMI, $\mathrm{kg} / \mathrm{m}^{2}$ & 12.5 & $9.8-15.9$ \\
Cord blood $\mathrm{pH}$ & 7.31 & $7.07-7.53$ \\
\hline
\end{tabular}

immunoassays were very low $[12,13]$. Hence, the assays are considered to be ideal for measuring steroid levels in the neonatal period. The interassay coefficient of variation was between 4.1 and $11.7 \%$ for the cortisol assay and between 5.0 and $9.8 \%$ for the 17-OHP assay. The intraassay coefficient of variation was between 5.3 and $8.8 \%$ for the cortisol assay and between 5.0 and $9.8 \%$ for the $17-\mathrm{OHP}$ assay.

\section{Results}

\section{Anthropometric and Clinical Data}

Anthropometric and clinical data of the neonates are summarized in Subjects and Methods and in table 1. As was expected, there was a correlation between gestational age and auxologic parameters (data not shown).

\section{Cortisol and 17-OHP Levels in 119 Healthy Neonates}

Cortisol and 17-OHP levels were measurable in saliva samples of all healthy neonates. Only on rare occasions was there too small a saliva volume to measure both hormones in duplicate. There were no differences between cortisol and 17-OHP levels in saliva from male and female neonates (data not shown). Normative data for salivary cortisol and 17-OHP levels in the neonatal period were generated (table 2, 3). Interestingly, there was a significant difference in salivary hormone levels when time of sampling was analyzed: significantly higher morning cortisol levels $(p=0.015)$ were found in the group in which samples had been taken 18-24 h after birth compared to the group where samples had been obtained 25$55 \mathrm{~h}$ after birth (fig. 1a). 17-OHP levels were significantly higher at all three times (morning $\mathrm{p}=0.001$, midday $\mathrm{p}=$ 0.017 , evening $p=0.038$ ) in the group where saliva samples had been taken 18-24 h after birth compared to the group where samples had been taken $25-55 \mathrm{~h}$ after delivery (fig. 1b). 

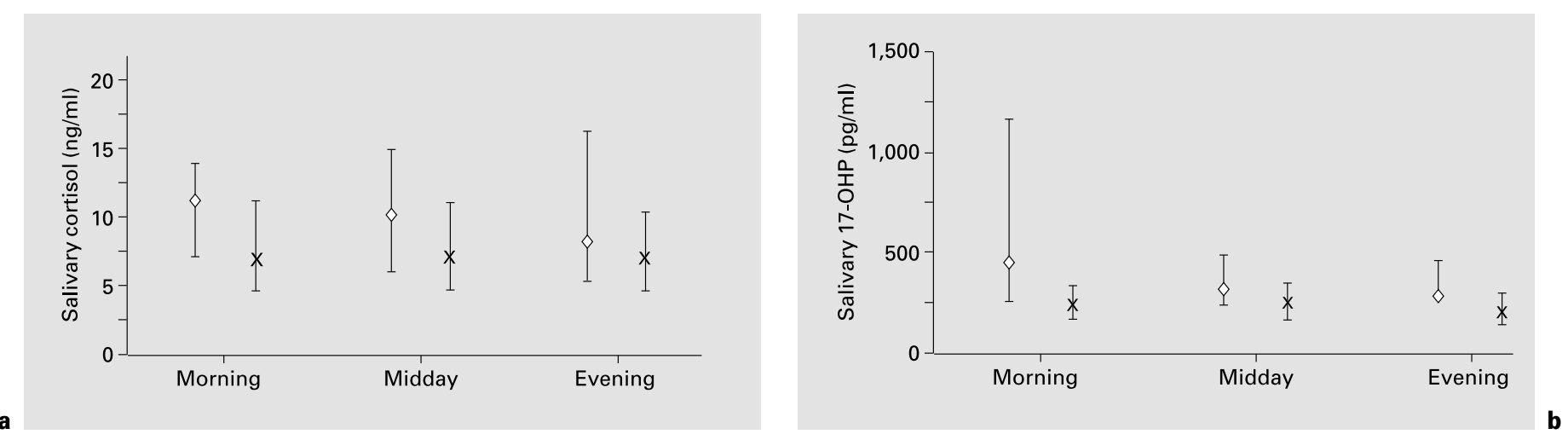

Fig. 1. Salivary cortisol (a) and 17-OHP levels (b) (median, 1st and 3rd quartile) in 119 healthy neonates with samples taken 18-24 $(\diamond)$ or 25-55 $(\times) \mathrm{h}$ after birth as described in Methods. In the group in which saliva samples were taken within $24 \mathrm{~h}$ after birth, morning, midday and evening 17-OHP and cortisol levels were significantly higher (morning $\mathrm{p}=0.001$, midday $\mathrm{p}=0.017$, evening $\mathrm{p}=0.04$ for $17-\mathrm{OHP}$; morning $\mathrm{p}=0.0015$ for cortisol) compared to the group in which samples were obtained later than $24 \mathrm{~h}$ after birth.

Table 2. Salivary cortisol levels $(\mathrm{ng} / \mathrm{ml})$ from healthy newborns according to time of sampling

\begin{tabular}{lccrc}
\hline & Mean \pm SD & Range & Median & $\mathrm{n}$ \\
\hline Samples taken & 18-24 h after birth & & & \\
Morning & $14.25 \pm 11.82$ & $2.21-49.46$ & 11.19 & 21 \\
Midday & $12.97 \pm 11.26$ & $2.62-46.55$ & 10.18 & 21 \\
Evening & $10.71 \pm 6.58$ & $3.42-23.45$ & 8.15 & 19 \\
\hline Samples taken $25-55$ h after birth & & & \\
Morning & $9.76 \pm 9.36$ & $2.41-60.40$ & 6.71 & 98 \\
Midday & $8.61 \pm 5.71$ & $2.37-28.66$ & 6.66 & 96 \\
Evening & $8.19 \pm 5.29$ & $1.21-34.66$ & 6.80 & 96 \\
\hline
\end{tabular}

\section{Lack of Circadian Rhythm of Cortisol and 17-OHP \\ Levels}

Neither saliva cortisol levels nor 17-OHP levels showed a circadian rhythm (fig. 1a, b). However, there was a significant correlation between 17-OHP levels in the morning, midday and evening (morning and midday $r=0.7$, midday and evening $r=0.67$, morning and evening $r=0.63$ ).

\section{Salivary Cortisol Levels as an Indicator of Stress in the Neonate}

Arterial cord blood $\mathrm{pH}$ values were significantly and inversely related to the duration of labor in the whole group of neonates considered to be healthy and not exposed to known unexpected stresses $(r=0.37, p>$
Table 3. Salivary 17-OHP levels $(\mathrm{pg} / \mathrm{ml})$ from healthy newborns according to time of sampling

\begin{tabular}{lrlll}
\hline & Mean \pm SD & Range & Median & $\mathrm{n}$ \\
\hline Samples taken & $18-24$ h after birth & & & \\
Morning & $623.1 \pm 481.4$ & $211.4-1723.3$ & 443.4 & 15 \\
Midday & $497.0 \pm 323.3$ & $183.4-1781.0$ & 323.3 & 17 \\
Evening & $397.5 \pm 260.6$ & $161.6-945.6$ & 287.6 & 10 \\
\hline Samples taken $25-55$ h after birth & & & \\
Morning & $305.6 \pm 222.4$ & $81.8-1528.9$ & 239.4 & 75 \\
Midday & $295.4 \pm 175.8$ & $116.4-983.6$ & 256.4 & 65 \\
Evening & $247.1 \pm 131.4$ & $92.3-739.2$ & 205.6 & 56 \\
\hline
\end{tabular}

0.001; data not shown). When we asked whether or not early cortisol levels were related to cord blood $\mathrm{pH}$ as an indicator of stress to the baby, a significant inverse relation was found in the group of infants where saliva samples had been taken within $24 \mathrm{~h}$ after birth $(\mathrm{r}=-0.52)$.

\section{Relation between Cortisol and 17-OHP Levels in \\ Saliva}

Since both cortisol and 17-OHP can be derived from the adrenal cortex of the infant, we have asked whether or not cortisol and 17-OHP levels in saliva of healthy neonates correlated. In fact, when parallel measurements of cortisol and 17-OHP in a total of 240 saliva samples were analyzed, there was a significant correlation between cortisol and 17-OHP levels in saliva $(\mathrm{r}=0.33, \mathrm{p}<0.0001)$. 


\section{Discussion}

Significantly higher salivary cortisol levels (mean $14.25 \mathrm{ng} / \mathrm{ml}$ ) were found in infants in which saliva had been sampled within the first $24 \mathrm{~h}$ after birth compared to the group of infants in which samples had been obtained $25-55 \mathrm{~h}$ after birth (mean $9.76 \mathrm{ng} / \mathrm{ml} ; \mathrm{p}<0.001$ ). We hypothesize that stress might contribute to high cortisol production of the neonate around birth and during delivery $[15,16]$. As a consequence, high cortisol saliva levels are present at birth and shortly thereafter. Due to the short half-life of cortisol, the high cortisol levels then decline rapidly during the first days of life. This assumption is in agreement with the findings of Bertrand et al. [14] who also found that cortisol levels declined after birth. They also investigated plasma cortisol levels of 75 neonates born at term. Maximum cortisol levels (40.5 $\mathrm{ng} / \mathrm{ml}$ ) were found shortly after birth, while a minimum $(6.7 \mathrm{ng} / \mathrm{ml})$ was observed between the $3 \mathrm{rd}$ and the 5 th day of life. These data are in accordance with our data in respect to saliva cortisol levels. In addition, Bespalova et al. [15] showed a decline in plasma cortisol levels within the first day of life in healthy neonates. Kurihara et al. [17] investigated saliva and plasma cortisol levels as an indicator of stress in neonates. Saliva cortisol levels showed a close correlation with plasma cortisol levels. Cortisol levels were positively related to stress in this group of neonates and infants.

In our study, low cord blood $\mathrm{pH}$ was related to longer duration of labor $(r=0.26, p=0.01)$. It has to be emphasized in this context that all infants studied by us were healthy, not asphyxiated and undistressed. Therefore the range of cord blood $\mathrm{pH}$ values is limited. It would be expected that in a study also involving ill or distressed neonates, a larger range of $\mathrm{pH}$ values would be found. Still there was a striking inverse relation between morning cortisol levels and cord blood $\mathrm{pH}(\mathrm{r}=-0.52, \mathrm{p}=0.017)$ in the group in which samples were taken within $24 \mathrm{~h}$ after birth. In the same group, there was a positive correlation between morning cortisol levels and body mass index $(\mathrm{r}=$ $0.58, \mathrm{p}=0.006)$. A multiple regression analysis showed that both correlations just exist because of two extremely high morning cortisol levels, which belong to two participants with extremely high body mass indices. We hypothesize that elevated salivary cortisol levels - as an expression of increased stress - might be related to high body mass index and near asphyxiation. This hypothesis should be tested in a prospective study involving distressed and asphyxiated as well as healthy neonates.
It is unclear at what time of infancy the circadian rhythmicity of cortisol release is first present. Some authors believe that rhythmicity starts as early as within the 2nd week of life [15, 18-23], while others state that the circadian rhythm of cortisol plasma levels is only present after 9 months of life [16]. In our study, no circadian rhythmicity was present in the whole group of 119 infants during the two days of the study period.

Reference values of plasma 17-OHP levels in neonates and infants have been reported previously $[24,25]$. We now provide normative data on 17-OHP saliva levels in neonates. In our study, 17-OHP salivary levels rapidly decreased from the first to the second day of life. This finding goes along with the data from Sippell et al. [20] who showed that 17-OHP blood levels decrease rapidly after birth [20,25]. In contrast to salivary cortisol levels, 17-OHP morning, midday and evening levels show a remarkable correlation: high morning levels are related to high midday and high evening levels. As a result of this, it could indeed be possible to take just one sample a day in order to, e.g. screen for congenital adrenal hyperplasia using saliva samples.

In conclusion, we have established normative data for salivary cortisol and 17-OHP in healthy neonates (table 2, 3; fig. 1). The salivary concentrations of both hormones decline rapidly after birth. No gender difference of salivary cortisol and 17-OHP levels was found. The determination of salivary cortisol levels in neonates might be a helpful measure to control for neonatal stress and birth asphyxia.

\section{Acknowledgments}

We wish to thank Christian Smit for helping collect samples. We also wish to express our sincere gratitude to the parents who gave permission to study their infants. We gratefully acknowledge the generous gift of saliva collecting devices (Salivette ${ }^{\circledR}$ ) by Sarstedt, Nümbrecht, Germany. 


\section{References}

1 Sizonenko PC, Aubert ML: Hypothalamopituitary axis and adrenal cortex: Fetoplacental unit; in Pediatric Endocrinology. Baltimore, Williams \& Wilkins, 1993, pp 127-128.

2 Ballard PL: Hormonal regulation of pulmonary surfactant. Endocr Rev 1989;10:165-181.

3 Sippell WG, Muller-Holve W, Dörr HG, Bidlingmaier F, Knorr D: Concentrations of aldosterone, corticosterone, 11-deoxycorticosterone, progesterone, 17-hydroxyprogesterone, 11-deoxycortisol, cortisol, and cortisone determined simultaneously in human amniotic fluid throughout gestation. J Clin Endocrinol Metab 1981;52:385-392.

4 Pang S, Levine LS, Cederqvist LL, Fuentes M, Riccardi VM, Holcombe JH, Nitowsky HM, Sachs G, Anderson CE, Duchon MA, Owens R, Merkatz I, New MI: Amniotic fluid concentrations of delta4- and delta5-steroids in fetuses with congenital adrenal hyperplasia due to 21 hydroxylase deficiency and in anencephalic fetuses. J Clin Endocrinol Metab 1980;51:223229.

5 New MI: Present status of prenatal diagnosis of congenital adrenal hyperplasia; in Lee PA, Kowarski AA, Migeon CJ (eds): Congenital Adrenal Hyperplasia. Baltimore, University Park Press, 1977, pp 511-526.

6 Allen JP, Cook DM, Kendall JW, McGilvra R: Maternal-fetal ACTH relationship in man. $\mathrm{J}$ Clin Endocrinol Metab 1973;37:230-234.

7 Simmer HH, Frankland M, Greipel M: On the regulation of fetal and maternal 16alpha-hydroxydehydroepiandrosterone and its sulfate by cortisol and ACTH in human pregnancy at term. Am J Obstet Gynecol 1975;121:646652.

8 Beitins IZ, Bayard F, Ances IG, Kowarski A, Migeon CJ: The metabolic clearance rate, blood production, interconversion, and transplacental passage of cortisol and cortisone in pregnancy near term. Pediatr Res 1973;7:509519.
9 Murphy BEP: Cortisol and cortisone in human fetal development. J Steroid Biochem 1979;11: 509-513.

10 Diczfalusy E: Endocrine functions of the human fetus and placenta. Am J Obstet Gynecol 1974;119:419-433.

11 Jaffe RB: Fetoplacental endocrine and metabolic physiology. Clin Perinatol 1983;10:669693.

12 Dressendörfer RA, Kiess W, Bidlingmaier F, Smit C, Rascher W, Klug I, Kistner A, Strasburger CJ: A time resolved fluorescence immunoassay for the determination of salivary 17 hydroxyprogesterone: Reference ranges throughout childhood and adolescence. Pediatr Res 1998;44:650-655.

13 Dressendörfer RA, Kirschbaum C, Rohde W, Stahl F, Strasburger CJ: Synthesis of cortisolbiotinconjugate and evaluation as a tracer in an immunoassay for cortisol measurement. J Steroid Biochem Mol Biol 1992;7:683-692.

14 Bertrand J, Bonnet H, Forest MG, Loras B, Rokicki W: Free cortisol of human plasma in the first three months of life. Biol Neonate 1990;57:21-29.

15 Kniazev IA, Sen'kevich OA, Bespalova VA, Saliaeva MV: Course of the early neonatal period and hormonal indicators in newborn infants from multiple pregnancies (in Russian). Pediatriia 1990;(10):24-29.

16 Rosendahl W, Schulz U, Teufel T, Irtel von Brenndorf C, Gupta D: Surgical stress and neuroendocrine response in infants and children. $\mathrm{J}$ Pediatr Endocrinol Metab 1995;8:187-194.

17 Kurihara H, Chiba H, Shimizu Y, Yanaihara T, Takeda M, Kawakami K, Takai-Kawakami $\mathrm{K}$ : Behavioral and adrenocortical responses to stress in neonates and the stabilising effects of maternal heartbeat on them. Early Hum Dev 1996;46:117-127.
18 Santiago LB, Jorge SM, Moreira AC: Longitudinal evaluation of the development of salivary cortisol circadian rhythm in infancy. Clin Endocrinol 1996;44:157-161.

19 Kiess W, Meidert A, Dressendörfer RA, Schriever K, Kessler U, König A, Schwarz HP, Strasburger CJ: Salivary cortisol levels throughout childhood and adolescence: Relation with age, pubertal stage and weight. Pediatr Res 1995;40:502-506.

20 Sippell WG, Dörr HG, Bidlingmaier F, Knorr D: Plasma levels of aldosterone, corticosterone, 11-deoxycorticosterone, progesterone, 17-hydroxyprogesterone, cortisol and cortisone during infancy and childhood. Pediatr Res 1980; 14:39-46.

21 Bettendorf M, Albers N, Bauer J, Heinrich UE, Linderkamp O, Maser-Gluth C: Longitudinal evaluation of salivary cortisol levels in fullterm and preterm neonates. Horm Res 1998; 50:303-308.

22 Walker RF, Hughes IA, Riad-Fahmy D: Salivary 17-OHP in congenital adrenal hyperplasia. Clin Endocrinol 1979;11:631-637.

23 Riad-Fahmy D, Read GF, Walker RF, Griffiths K: Steroids in saliva for assessing endocrine function. Endocr Rev 1982;3:367-395.

24 Otten BJ, Wellen JJ, Rijen JC, Stoelinga GB, Benraad TJ: Salivary and plasma androstenedione and 17-hydroxyprogesterone levels in congenital adrenal hyperplasia. J Clin Endocrinol Metab 1983;57:1150-1154.

25 Sippell WG, Becker H, Versmold HT, Bidlingmaier F, Knorr D: Longitudinal studies of plasma aldosterone, corticosterone, deoxycorticosterone, progesterone, 17-hydroxyprogesterone, cortisol, and cortisone determined simultaneously in mother and child at birth and during the early neonatal period. I. Spontaneous delivery. J Clin Endocrinol Metab 1978;46: 971-985. 